\title{
Developmental versus sensory deficit effects on perceptual processing in the reading disabled
}

\author{
JULIE R. BRANNAN and MARY C. WILLIAMS \\ University of New Orleans, New Orleans, Louisiana
}

\begin{abstract}
Thirty children and 5 adults participated in two experiments designed to compare visual processing in normal and reading disabled children. The children were aged 8, 10, and 12 years. In Experiment 1, subjects were asked to detect the temporal order of two briefly presented stimuli. In Experiment 2, subjects sorted cards containing bracket stimuli that did or did not produce perceptual grouping effects. Poor readers required more time to make accurate temporal order judgments and showed stronger perceptual grouping effects. For both good and poor readers, the amount of time necessary to make a correct temporal order judgment decreased, and perceptual grouping effects became weaker with age. However, the magnitude of the difference between the groups did not lessen with age. These results suggest that there are visual processing differences between good and poor readers that do not appear to correct by age 12 .
\end{abstract}

A long-standing debate exists over whether children with reading disabilities suffer from a processing deficit of some kind (first proposed by N. D. Bryant, 1964) or a maturational lag or delay (e.g., Money, 1966; Satz \& Sparrow, 1970). This issue is particularly important for efforts toward remediation; if poor readers have a lag in some process crucial to the development of reading ability that is corrected (or compensated for) with time, intervention would be of a different nature than if poor readers maintain a deficit with no spontaneous recovery.

Recent research has suggested that many reading disabled children show visual processing differences at an early stage of processing. For example, Lovegrove, Martin, and Slaghuis (1986) reported that poor readers have longer persistence durations at low spatial frequencies than do controls, are less sensitive to contrast at low spatial frequencies but are equally or more sensitive at high spatial frequencies, and are less sensitive to all rates of the phase alternation of a grating. Several investigators have reported differences in visually evoked potentials between good and poor readers, particularly when measurements are taken from the parietal area (e.g., Connors, 1970; Mecacci, Sechi, \& Levi, 1983; Preston, Guthrie, \& Childs, 1974; Sobotka \& May, 1977; Symann-Louett, Gascon, Matsumiya, \& Lombroso, 1977).

Other investigators have explored the perceptual consequences of such a sensory processing deficit. Stanley and Hall (1973) and Clifton-Everest (1976) reported that poor readers show deficits in the ability to sequence information in the visual field. Mason (1980) found that poor readers require more time than normal readers to encode information about the location of a letter in an ar-

Portions of this research were presented at the 1987 meeting of the Association for Research in Vision and Ophthalmology, Sarasota, FL. We would like to thank James $G$. May for helpful suggestions on an earlier draft of this paper. Correspondence should be addressed to J. R. Brannan at the VEP Laboratory, Mt. Sinai Medical Center, One Gustave Levy Place, New York, NY 10129. ray. Other reports suggest that poor readers show a relative inability to selectively attend (Williams \& Bologna, 1985), a deficit in allocating attention across visual space (Brannan \& Williams, 1987), and a deficit in the temporal processing of two word stimuli (May, Williams, \& Dunlap, in press). Williams, Brannan, and Lartigue (1987) and Williams and Brannan (1986) demonstrated that differences in poor readers' versus good readers' performance on visual search and global precedence tasks are lessened when very high spatial frequencies are diminished. These results all point toward fundamental visual processing differences between reading disabled and normally reading children.

The traditional reading research paradigm matches children who are above average or average in reading ability with poor readers of the same chronological age. Backman, Mamen, and Ferguson (1984) pointed out that any differences observed between these groups may be influenced by the differences in reading skill. They proposed a new design, referred to as the "reading level design." In the reading level design, reading disabled children are matched with younger, normally reading children who are reading at the same reading level. A chronological match is also made. Comparisons are then made between children who are of the same chronological age but have different reading abilities (the traditional comparison), and between children who are equal in reading abilities but different in chronological age. Although the reading level design does have its weaknesses (see P. Bryant \& Goswami, 1986), matches for both reading level and chronological age make an important step toward separating age-related from reading-related variables (Mamen, Ferguson, \& Backman, 1986).

Although the evidence for visual processing differences in reading ability is strong, developmental issues have not been sufficiently explored. To answer the lingering question of deficit versus delay, more cross-sectional studies covarying perceptual and developmental factors are 
needed. The experiments described here compared temporal and perceptual abilities in 8-, 10-, and 12-year-old children with good and poor reading abilities. The reading level comparison is made to compare the relative effects of reading skill on particular visual tasks.

\section{EXPERIMENT 1}

Reading is a temporal task, composed of fixation-saccade sequences (see Breitmeyer, 1983). May et al. (in press) required children with good and poor reading abilities to detect the temporal order of two successively presented word stimuli. They reported that poor readers required significantly more time to make an accurate temporal order judgment. The following experiment was similar to that of May et al. in procedure, and measured the performance of good and poor readers at different ages to investigate possible maturational effects. Nonword stimuli were used in addition to word stimuli, to explore possible differential temporal processing of word versus nonword stimuli. Due to time limitations, only two word and two nonword stimuli were used.

\section{Method}

\section{Subjects}

Thirty children from a local New Orleans school, 5 good and 5 poor readers at each of three age levels $(8,10$, and 12 years), participated as subjects. Table 1 presents the mean age, range of ages, and the numbers of males and females for each group. Five adults with normal reading abilities served as a comparison group.

Children classified as good readers were reading at least 1 year above grade level, as measured by the Spache Diagnostic Reading Scales. Poor readers were reading at least 1 year below grade level. According to their school records, all children were of normal or above normal intelligence (as measured by the Stanford-Binet), were performing at average or above average levels in all school subjects except reading or reading-related subjects, and had normal or corrected-to-normal 20/20 (Snellen) visual acuity.

\section{Stimuli and Apparatus}

Stimuli consisted of two word sequences (BOX and FOX) or two three-character nonword symbols ([\#] and [\&]) presented on a Zenith Z-100 microcomputer $1.0^{\circ}$ of visual angle to the left and right of a center fixation cross. All stimuli subtended $.95^{\circ}$ of visual angle vertically and $1.85^{\circ}$ horizontally, and consisted of green letters $\left(75 \mathrm{~cd} / \mathrm{m}^{2}\right)$ on a dark background $\left(20 \mathrm{~cd} / \mathrm{m}^{2}\right)$. Stimuli were clearly suprathreshold. The subjects viewed the screen binocularly at a viewing distance of $30 \mathrm{~cm}$.

Table 1

Mean Age, Range of Ages, and Sex Breakdown for Each Subject Group

\begin{tabular}{lrrrrr}
\hline Subject Group & Age & Mean Age & \multicolumn{1}{c}{ Range } & Sex \\
\hline Poor Readers & 8 & 8.34 & 8,2 to 8,10 & $2 \mathrm{~F}, 3 \mathrm{M}$ \\
Poor Readers & 10 & 9.94 & 9,6 to 10,5 & $2 \mathrm{~F}, 3 \mathrm{M}$ \\
Poor Readers & 12 & 11.94 & 11,6 to 12,5 & $2 \mathrm{~F}, 3 \mathrm{M}$ \\
Good Readers & 8 & 8.44 & 8,6 to 8,10 & $3 \mathrm{~F}, 2 \mathrm{M}$ \\
Good Readers & 10 & 10.46 & 10,4 to 10,7 & $4 \mathrm{~F}, 1 \mathrm{M}$ \\
Good Readers & 12 & 12.16 & 11,6 to 12,4 & $3 \mathrm{~F}, 2 \mathrm{M}$ \\
Adults & N/A & 28.2 & 19 to 31 & 3F,2M \\
\hline
\end{tabular}

Note $-F=$ female; $M=$ male.

\section{Procedure}

On each trial, two stimuli were presented in brief succession to the left and right of a center fixation point. The first stimulus appeared to the left of the fixation point on exactly half of the trials, and the first stimulus appeared to the right on the remainder of the trials. The subject was asked to point to the side of the screen on which the first stimulus had appeared. The first stimulus on each trial was presented for 900 msec, with the second stimulus following at a varying duration. The stimuli had simultaneous offsets. The minimum stimulus onset asynchrony (SOA), in milliseconds, required for each subject to detect which of the two stimuli appeared first with $75 \%$ accuracy was obtained. All subjects were given 32 practice trials at an SOA of $160 \mathrm{msec}$, followed by another set of practice trials at an SOA of $40 \mathrm{msec}$. The experimenter then selected an SOA close to estimated threshold. After 32 trials at this SOA, accuracy was automatically calculated. If accuracy was less than $75 \%$, the SOA was increased by $1 / 2$ octave. If accuracy was greater than $75 \%$, the SOA was decreased by $1 / 2$ octave. This procedure was repeated until the SOA yielding $75 \%$ accuracy was determined by interpolation.

The two stimulus types (words and nonwords) were run in separate blocks, with the order of the blocks randomized. Equal numbers of the four target alternatives were presented in each block. Two thresholds were obtained for each subject, one for word stimuli (BOX and FOX) and another for nonword stimuli ([\#] and [\&]),

\section{Results}

\section{Analysis of Variance}

A three-way analysis of variance (ANOVA) with two between-group factors (subject group and age), one within-group factor (word or nonword stimuli), and an isolated control group (adult subjects) was performed on the threshold data. The main effect for groups (good readers vs. poor readers) was significant $[F(1,28)=$ $32.842, p<.01]$, suggesting that the subject groups varied in their threshold for temporal order judgments. The means for each group in each condition are presented in Figure 1 (for word stimuli) and Figure 2 (for nonword stimuli). At each age, good readers required significantly less time than poor readers to make a judgment about the temporal order of two stimuli, regardless of stimulus type (Newman-Keuls multiple comparison tests, $p<.05$ ).

The main effect for age $(8,10$, or 12 years) was also significant $[F(2,28)=9.577, p<.01]$. This indicates that, overall, children of different ages differed in the amount of time required to make accurate temporal order judgments. For both word and nonword stimuli, temporal order judgments decreased with age. Eight-year-old good readers required more time to detect temporal order than did older good readers or adults (Newman-Keuls multiple comparison tests, $p<.05$ ). Among poor readers, 8 and 10-year-olds were less sensitive to the detection of temporal order than were 12-year-olds (Newman-Keuls multiple comparison tests, $p<.05$ ). Poor readers of all ages were less sensitive than adults in detecting temporal order (Newman-Keuls multiple comparison tests, $p<.05)$. This was true for both stimulus types.

The main effect for stimulus type (word vs. nonword) did not reach significance. The interaction between sub- 


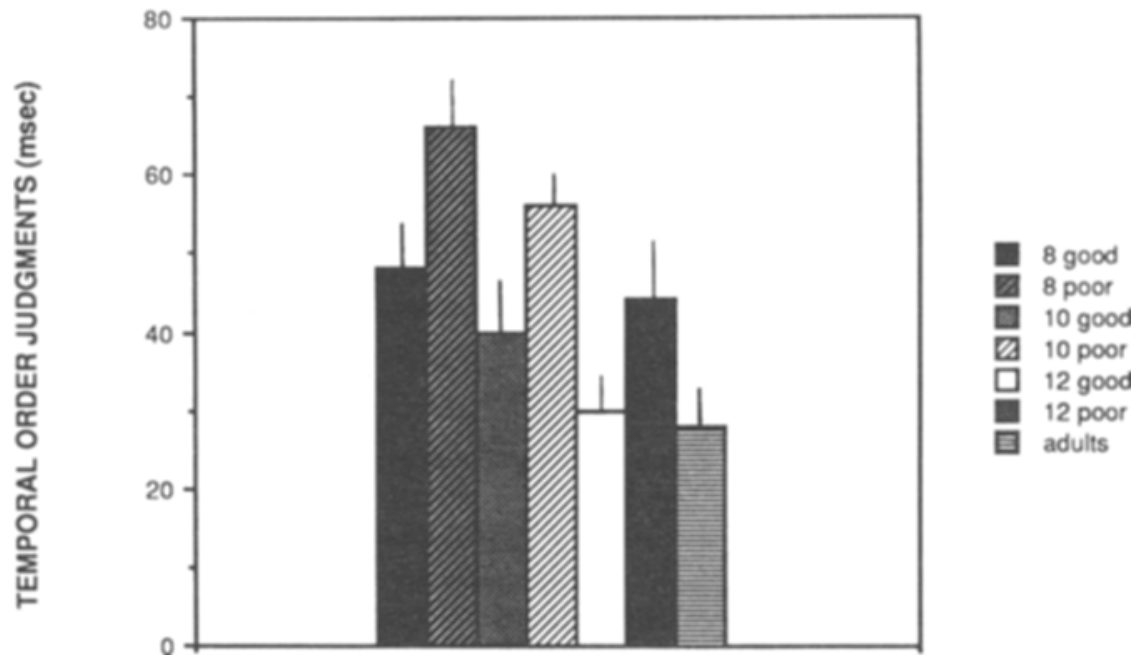

Figure 1. Threshold for temporal order judgments to word stimuli in good and poor young readers and adult subjects. The shortest stimulus onset asynchrony (in msec) at which $75 \%$ accuracy in detecting the temporal order of two briefly presented word stimuli is obtained is shown for good readers aged 8,10 , and 12 , and for adults.

ject groups and stimulus types was significant $[F(1,28)$ $=3.909, p<.05]$. Good readers tended to have lower thresholds for the temporal order of nonword stimuli than for that of word stimuli, whereas poor readers showed equal or longer temporal order judgments to nonword stimuli than to word stimuli.

Interactions between subject group and age, age and stimulus type, and subject group, age, and stimulus type were not significant. Good and poor readers showed the same age-related decrease in the amount of time needed to detect temporal order, but a significant deficit in the performance of poor readers remained across all age ranges.

\section{Pearson Correlations}

The ability to make accurate temporal order judgments for all groups combined was highly correlated with reading level $(p<.05)$. The correlation between reading

\section{Temporal order judgments for nonword stimuli}

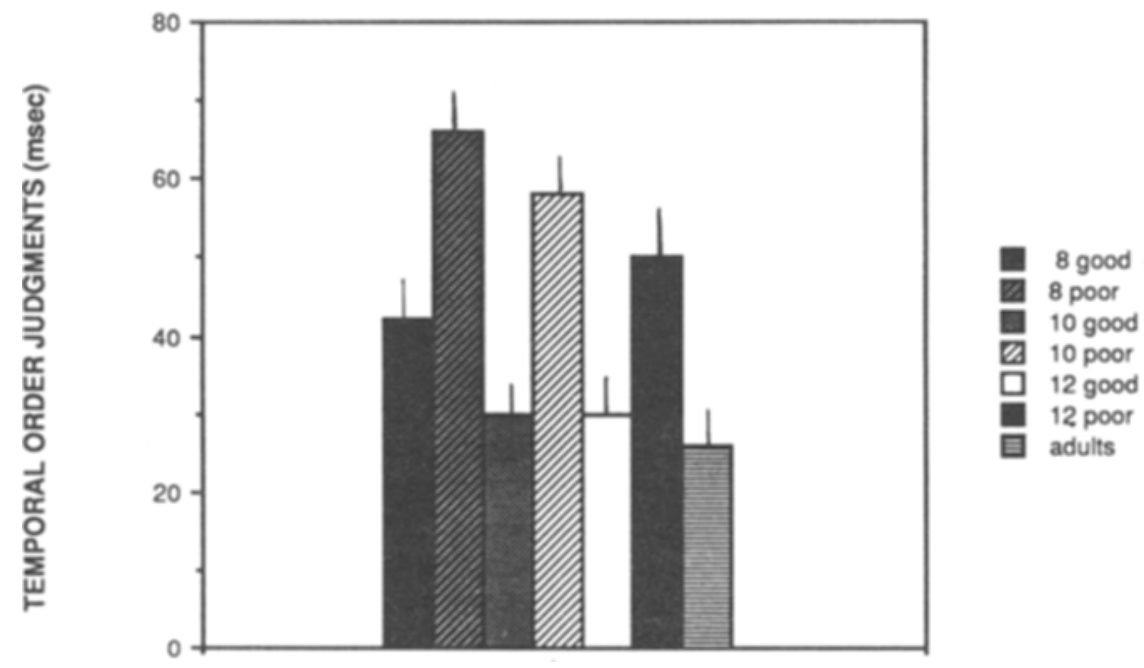

Figure 2. Threshold for temporal order judgments to nonword stimuli in good and poor young readers and adult subjects. The shortest stimulus onset asynchrony (in msec) at which $75 \%$ accuracy in detecting the temporal order of two briefly presented nonword stimuli is obtained is shown for poor readers aged 8,10 , and 12 , and for adults. 
level and temporal order judgments for nonwords was -.66 , indicating that $44 \%$ of the variance in reading level was accounted for by taking into consideration thresholds for nonword temporal order judgments. The correlation between reading level and temporal order judgment threshold for word stimuli was -.55 , indicating that $30 \%$ of the variance in reading level was accounted for by taking into consideration thresholds for word temporal order judgments. These correlations are surprisingly high; however, they suggest that this task is very similar to the reading process.

\section{Reading Level Comparisons}

The significant correlations between reading level and the ability to make an accurate temporal order judgment for all subjects suggest that temporal order judgments are a valid measure. To compare the relative effects of reading skill on performance of the temporal order task between subject groups, post hoc comparisons were made between 10-year-old poor readers and 8-year-old good readers (reading at grade levels 4.3 and 4.9 , respectively), and between 12-year-old poor readers and 10-year-old good readers (reading at grade levels 6.1 and 6.8, respectively). Although the reading level matches are not perfect, the difference in reading level between matched good and poor readers $(0.6-0.7$ years) is significantly less than the difference between age groups ( 2.0 years). If children of different ages who are reading at roughly the same level show equivalent performance on these measures, this suggests that the overall better reading skills of good readers are strongly influencing the performance differences observed between good and poor readers of the same age. If a difference remains when children are matched for reading ability, some fundamental processing difference between the groups is likely.

Eight-year-old good readers required significantly less time to detect accurately the temporal order of two word or nonword stimuli than did 10 -year-old poor readers who were reading at the same level (Newman-Keuls multiple comparison tests, $p<.05$ ). Ten-year-old good readers also required significantly less time to detect temporal order than did 12-year-old poor readers (Newman-Keuls multiple comparison tests, $p<.05$ ). This suggests that the difference in ability to make temporal order judgments between good and poor readers is not due primarily to reading skill differences; there seems to be some fundamental temporal processing difference between the groups.

\section{Discussion}

The main finding of this experiment was that poor readers require a longer time interval than good readers and adults to detect the temporal order of two briefly presented stimuli. This holds true for both word and nonword stimuli. This corroborates the description by May et al. (in press) of temporal order judgments in good and poor readers. In general, good readers had lower asyn- chrony thresholds for nonwords than words, whereas poor readers had equal thresholds for both stimulus types. It is interesting to speculate on this interaction; perhaps good readers, as more practiced readers, are more likely to process the words, whereas poor readers treat words no differently from nonwords.

Although good and poor readers showed the same trend toward increased ability to make quick and accurate temporal order judgments with age, this developmental effect did not account for performance differences between good and poor readers. Sensitivity to temporal order increased with age in both groups, but the magnitude of the difference between the groups did not decrease with age. This finding suggests that a temporal processing deficit of some kind that cannot be accounted for by a developmental lag exists in the poor readers tested.

\section{EXPERIMENT 2}

Experiment 1 showed that poor readers have a deficit in early temporal processing operations. It is possible that such a deficit has perceptual consequences. Experiment 2 measured a perceptual operation-perceptual groupingthat occurs early in visual processing. Perceptual grouping involves the linking of elements into figures and regions. Williams and Bologna (1985) found that poor readers, compared with good readers and adults, show very strong perceptual grouping effects and a relative inability to selectively attend to elements within perceptual groups. Featural processing involved in reading would necessarily require the ability to selectively attend to relevant figural elements within words. In Experiment 2, we used the procedures of Pomerantz and Garner (1973) to investigate the effect of development on good and poor readers' abilities to selectively attend.

\section{Method}

\section{Subjects}

The same subjects described in Experiment 1 participated in Experiment 2 .

\section{Stimuli}

The stimuli described by Pomerantz and Garner (1973) and Williams and Bologna (1985) were used (shown in Figure 3). Each bracket stimulus was composed of two elements. The bracket stimuli were drawn with black India ink on stiff white cards. Each bracket was $8 \mathrm{~mm}$ tall $\times 4 \mathrm{~mm}$ wide, and the spacing between the brackets was $4 \mathrm{~mm}$. At a typical viewing distance of $30 \mathrm{~cm}$, the stimuli subtended $1.5^{\circ}$ of visual angle.

\section{Conditions}

Stimuli were arranged into four decks of 32 cards each, with each deck representing a different experimental condition. Previous research (e.g., Pomerantz \& Garner, 1973) has shown that the stimulus [ ] produces large perceptual grouping effects in normal subjects and that the stimulus [ - does not produce perceptual grouping effects. The task was speeded card sorting.

Control conditions. In the two control conditions, only the relevant (right) element varied while the irrelevant (left) element remained constant. Each deck of cards contained the stimuli [ ] and 
A.

Control Condition

[ ] vs. [ [

Orthogonal Condition

[] or $]]$ vs. [ [ or $]$ [

B. Control Condition

$[\rightarrow \quad$ vs. $\quad[-$

Orthogonal Condition

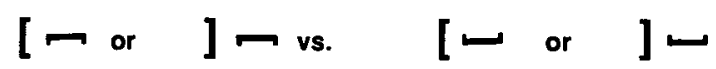

Figure 3. Bracket stimuli used in Experiment 2. The stimuli in panel A produce grouping effects; the stimuli in panel $B$ do not.

[ [, 16 of each, or [ - and $[-, 16$ of each. The subjects were asked to sort the cards into two piles on the basis of the right element alone.

Orthogonal conditions. In this condition, both the left and right elements of the bracket stimuli varied, but in an independent orthogonal manner. In the grouping condition, the deck of 32 stimuli contained the 4 stimuli shown in panel A of Figure 3, 8 of each. The subjects were asked to sort the cards on the basis of the right (relevant) element; the left element varied orthogonally. For the nongrouping condition, the deck of 32 stimuli contained the stimuli shown in panel B of Figure 3, 8 of each. In the grouping condition, the subjects were instructed to sort the stimuli [ ] and ] ] into one pile and the stimuli [ [ and ] [ into another pile. If the subjects are able to attend selectively to the relevant element, then the variation of the left irrelevant element should not interfere with sorting performance. Thus, if selective attention is possible, the sorting times in the control and orthogonal conditions should be similar. If selective attention is difficult or impossible, there should be interference from the irrelevant element in the orthogonal condition and sorting times should be longer. The difference in sorting times in the control and orthogonal conditions is an index of whether and to what degree perceptual grouping occurs. The stimuli shown in panel B of Figure 3 vary orthogonally but do not group; thus, selective attention should be possible, and there should be no differences between performance on these stimuli and performance on the control stimuli.

Color condition. To preclude the possibility that performance differences between good and poor readers are due to differences in visual-motor performance rather than differences in perceptual processing, a condition in which the subjects were asked to sort color-coded cards was included. A deck of 32 cards was used, 16 with a blue dot in the center and 16 with a purple dot in the center. This condition provided an index of differences in overall performance in the card-sorting task, independent of perceptual grouping effects.

\section{Procedure}

The task for all conditions was to quickly sort a deck of cards into two piles. The subjects were handed a deck of cards, along with an instruction card that indicated which stimuli were to be put into which response pile. The subjects were allowed to hold the deck of cards in the preferred hand and were instructed to sort as quickly as possible without making any errors. Sorting time was measured by the experimenter with a stopwatch. Classification errors were also recorded (there were no differences between good and poor readers regarding the number or type of errors made). The subjects received one practice trial for each condition, and then were asked to sort once under each condition. The order of the conditions was counterbalanced across subjects.

Since Williams and Bologna (1985) found that there were differences in the sorting strategies assumed by different subject groups, the subjects were given the optimal sorting strategy prior to performing the task; that is, they were told to sort on the basis of the right element and to ignore the left. Thus performance differences are not likely to be related to strategy differences.

\section{Results}

\section{Color Condition}

A two-way ANOVA with two between-group effects (subject group and age) was performed on the sorting times for the color-sorting task. The main effect of subject group was not significant. Thus, there is no evidence that ability to perform a card-sorting task differed across our subject populations. In fact, the overall sorting time for poor readers $(24 \mathrm{sec})$ was slightly faster than that of good readers $(25 \mathrm{sec})$. The main effect for age did achieve significance ( $F$ ratios for all significant analyses in this experiment can be found in Table 2), suggesting that cardsorting ability varies with age. Mean sorting times were $26.90,23.50$, and $21.40 \mathrm{sec}$ for 8-, 10-, and 12-year-olds, respectively. Newman-Keuls planned comparisons revealed a significant difference between the sorting times for the 8-year-olds and those of the older groups. The interaction of subject group and age was not significant, suggesting that there is no difference between good and poor readers in the developmental trend toward decreased cardsorting time.

\section{Grouping Effects}

A four-way ANOVA with two between-group factors (subject group and age) and two within-group factors

Table 2

F Ratios for Experiment 2

\begin{tabular}{|c|c|c|}
\hline Effect & $d f$ & $F$ \\
\hline \multicolumn{3}{|l|}{ Color Condition } \\
\hline Main Effect for Age & 2,28 & 5.392 \\
\hline \multicolumn{3}{|l|}{ Grouping Condition } \\
\hline $\begin{array}{l}\text { Main Effect for Subject Group } \\
\text { Main Effect for Age } \\
\text { Main Effect for Stimulus Type } \\
\text { Effect for Orthogonal vs. Control } \\
\text { Subject Group } \times \text { Stimulus Type } \\
\text { Subject Group } \times \text { Condition } \\
\text { Stimulus Type } \times \text { Condition } \\
\text { Subject Group } \times \text { Stimulus } \times \text { Condition }\end{array}$ & $\begin{array}{l}2,28 \\
2,28 \\
1,28 \\
1,28 \\
1,28 \\
1,28 \\
1,28 \\
1,28\end{array}$ & $\begin{array}{r}15.695 \\
6.798 \\
110.531 \\
171.661 \\
23.707 \\
34.40 \\
110.139 \\
31.096\end{array}$ \\
\hline \multicolumn{3}{|c|}{ Grouping Effect Condition } \\
\hline Main Effect for Subject Group & 1,28 & 38.438 \\
\hline
\end{tabular}

Note-All $F$ ratios are $p<.01$. 
(whether or not the stimuli grouped and control vs. orthogonal conditions) was performed on the card-sorting times. The main effect of subject group was significant, demonstrating that card-sorting times varied across subject groups. The main effect of age was significant, showing that sorting times change with age. The main effect of stimulus type ([] versus [ - ) was significant. This result shows that card-sorting times are different for the two stimulus types. Overall, there were no significant differences between the orthogonal and control conditions for the [ - stimuli, but the difference between orthogonal and control conditions for the [] stimuli was significant. This control-orthogonal difference can then be taken as a valid index of perceptual grouping.

The interactions between subject group and stimulus type and between-subject group and condition were significant, suggesting that subject groups differed in their card-sorting ability depending on whether or not the stimuli grouped or not and on whether the elements of the stimulus varied orthogonally. The interaction between stimulus type and condition was significant, indicating that card sorting between control and orthogonal conditions differed when the stimuli grouped and when they did not. The three-way interaction between subject group, stimulus type, and condition was significant, indicating that subject groups varied in their card-sorting times depending on whether the stimuli grouped and on whether they varied orthogonally.

None of the interactions involving age as a variable were significant. Coupled with the significant main effect of age, these results suggest that good and poor readers do not differ in their developmental trend toward shorter sort- ing times with increased age, and that subject groups maintain an overall difference in sorting times that does not change with age.

A two-way ANOVA with two between-group factors (subject group and age) was performed on the grouping effect data, defined as the difference in sorting times between the control and orthogonal conditions when the stimuli produced grouping effects. The main effect of subject group was significant, indicating that subject groups differed in the magnitude of their grouping effects. The main effect of age and the interaction of subject group and age did not achieve significance; these results suggest that the grouping effect does not vary consistently with age, and that subject groups do not vary in their agerelated changes in the grouping effect.

The grouping effect for all subjects is plotted in Figure 4. Eight-year-old good readers had significantly larger grouping effects than 10- or 12-year-old good readers or adults (this and all subsequent significant post hoc tests are Newman-Keuls multiple comparison tests, $p<.05$ ). In general, grouping effects decline with age for good readers. Poor readers do not significantly differ in grouping effect according to age ranges, but are significantly different from normally reading adults. Good and poor readers do not differ in grouping effect at age 8, but good readers evidence significantly smaller grouping effects at ages 10 and 12 .

\section{Pearson Correlations}

The correlation between reading level and perceptual grouping effects was significant $(p<.05)$. The correlation was -.65 , indicating that $42 \%$ of the reading level

Perceptual grouping effects for all subjects

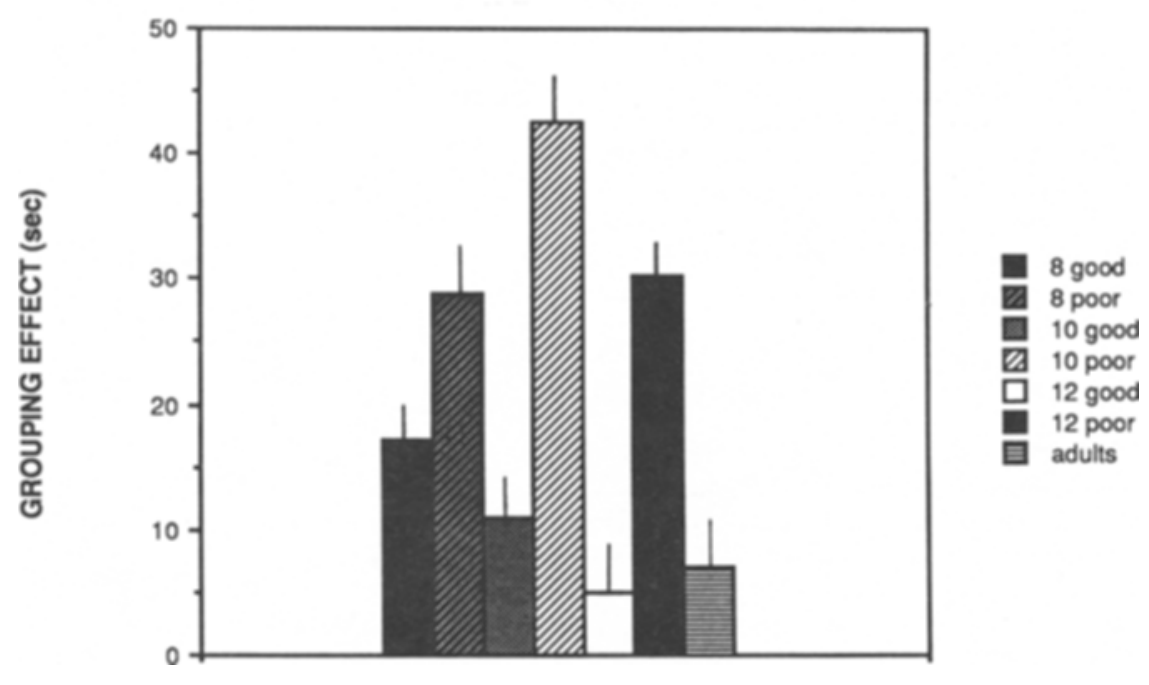

Figure 4. Grouping effects for good and poor young readers and adult subjects. Grouping effect is defined as the amount of time necessary to sort cards in the control condition minus the card-sorting time in the orthogonal condition for the same stimuli. Grouping effects are shown for good and poor readers aged 8,10 , and 12, and for adults. 
variance was accounted for by taking into consideration grouping effects.

\section{Reading Level Comparisons}

Eight-year-old good readers had significantly smaller perceptual grouping effects than 10-year-old poor readers who were reading at the same level. Good readers who were 10 years old also had significantly smaller perceptual grouping effects than 12-year-old poor readers. These results again suggest that differences in perceptual grouping effects between good and poor readers are not primarily due to differences in reading level, but that there is a fundamental processing difference that remains when groups are equated for reading skill.

\section{Discussion}

The main finding of this experiment is that good readers show a trend toward smaller perceptual grouping effects with age and, therefore, an increased ability for selective attention, whereas poor readers do not. Poor readers show larger perceptual grouping effects than good readers at ages 10 and 12 and than adults. Williams and Bologna (1985) described the implications that differences in perceptual grouping could have for poor readers. Strong perceptual grouping effects suggest that there is a failure to attend selectively to the relevant element and to ignore the irrelevant element. This failure of selective attention suggests that the stimulus is being processed as a whole or a unit. As described by various researchers (e.g., Breitmeyer \& Ganz, 1976; Broadbent, 1977; Neisser, 1967; Weisstein, Ozog, \& Szog, 1975), perceptual grouping is accomplished by a holistic, preattentive process. The results of this experiment then agree with those of Experiment 1 ; the poor readers in this study show basic visual processing differences from good readers and normally reading adults.

The most intriguing finding of this experiment involves the development of perceptual grouping in good and poor readers. There was a significant main effect for age; in general, perceptual grouping effects decreased with age. However, the magnitude of the difference between good and poor readers did not decrease with age. Planned comparisons revealed no significant differences for grouping effects in 8-year-old good and poor readers, but poor readers had significantly larger grouping effects at ages 10 and 12 . This finding agrees with Experiment 1 in that there does not seem to be a maturational lag that is being corrected with age; in fact, in this experiment, the difference between the groups increases with age. Perhaps the development of analytic information processing requires normal functioning earlier in the visual processing sequence. If early visual processing is sluggish, as indicated by the temporal processing data of Experiment 1, poor readers may then be overly restricted to the global, holistic processing mode and may be unable to develop the ability to perform a more detailed analysis.

\section{CONCLUSIONS}

The purpose of these experiments was to explore the effects of age and reading ability on performance of a primarily temporal task (the ability to make an accurate judgment about the temporal order of two briefly presented stimuli) and a primarily perceptual task (perceptual grouping). Differences that could not be explained by variations in reading skill were found between good and poor readers on both tasks. These findings provide additional evidence for the proposal that visual processing differences exist between normal and disabled readers. Recently, it has been asserted that reading disabled children do not show a disorder in visual perception (e.g., Vellutino, 1987). Such reports tend to rely on visual memory tasks and static (vs. dynamic) visual displays.

The most novel aspect of this investigation involved the use of good and poor readers at different ages to explore possible developmental differences. In both experiments, there were significant effects for age, but no age $\times$ subject group interactions. This suggests that developmental or maturational effects are not driving the between-group differences. Although good and poor readers show the same trend toward lower thresholds for temporal order judgments with age, the magnitude of the difference between the groups does not diminish. In fact, for the grouping task, the difference between good and poor readers increased with age. These findings corroborate Brannan and Williams's (in press) recent findings that poor readers have lower thresholds to full-field flicker than do good readers and that this difference does not significantly decrease with age. However, if good readers have not reached their asymptote at age 12 (as they may not have in the temporal order task), there is still the possibility that poor readers could catch up at a later age. More research with expanded age groups should address this problem.

Pearson correlations indicated that $44 \%$ of the variance in reading ability could be accounted for by taking into consideration thresholds for nonword temporal order judgments. Perceptual grouping effects could account for $42 \%$ of the reading ability variance. Brannan and Williams (in press) reported that variation in thresholds for flicker could account for $58 \%$ of children's reading ability. These results could have important implications for early targeting of children with reading problems. If perceptual tasks exist that can with some accuracy predict reading problems before the child has had extensive practice in reading, perhaps early intervention could lead to more effective remediation. Future investigations should test large numbers of prereaders on these perceptual tasks and determine whether the tasks have any predictive validity for reading ability.

Together, the findings of the present study suggest a basic deficit in temporal processing in poor readers. The temporal response of poor readers appears to be sluggish compared with that of normal readers. Further investi- 
gations will be necessary to delineate more precisely the nature and consequences of such a processing deficit.

\section{REFERENCES}

Backman, J. E., Mamen, M., Ferguson, H. B. (1984). Reading level design: Conceptual and methodological issues in reading research. Psychological Bulletin, 96, 560-568.

Brannan, J. R., Williams, M. C. (1987). Allocation of visual attention in good and poor readers. Perception and Psychophysics, 41, 23-28.

Brannan, J. R., Williams, M. C. (in press). The effects of age and reading ability on flicker threshold. Clinical Vision Sciences.

BREITMEYER, B. (1983). Sensory masking, persistence, and enhancement in visual exploration and reading. In K. Rayner (Ed.), Eye movements in reading (pp. 3-30). London: Academic Press.

Breit MEYER, B. G., \& GANZ, L. (1976). Implications of sustained and transient channels for theories of visual pattern masking, saccadic suppression, and information processing. Psychological Review, 87, 52-69.

Broadbent, D. (1977). The hidden preattention process. American Psychologist, 32, 109-118.

Bryant, N. D. (1964). Characteristics of dyslexia and their remedial implications. The Exceptional Child, 31, 195-197.

Bryant, P., Goswami, U. (1986). Strengths and weaknesses of the reading level design: A comment on Backman, Mamen, and Ferguson. Psychological Bulletin, 100, 101-103.

Clifton-Everest, I. M. (1976). Dyslexia: Is there a disorder of visual perception? Neuropsychologia, 14, 491-494.

Connors, C. K. (1970). Cortical visual evoked response in children with learning disorders. Psychophysiology, 7, 418-428.

Lovegrove, W., Martin, F., \& Slaghuis, W. (1986). A theoretical and experimental case of a visual deficit in specific reading disability. Cognitive Neuropsychology, 3, 225-267.

Mamen, M., Ferguson, H. B., \& Backman, J. E. (1986). No difference represents a significant finding: The logic of the reading level design. A response to Bryant and Goswami. Psychological Bulletin, 100, 104-106.

MASON, M. (1980). Reading ability and the encoding of location information. Journal of Experimental Psychology: Human Perception \& Performance, 6, 89-98.
MaY, J., Williams, M., \&unlaP, W. (in press). Temporal order judgments in good and poor readers. Neuropsychologia.

MeCACCI, L., SECHI, E., \& Levi, S. (1983). Abnormalities of visual evoked potentials by checkerboards in children with specific reading disability. Brain \& Cognition, 2, 135-143.

MoNEY, J. (1966). On learning and not learning to read. In J. Money (Ed.), The disabled reader: Education of the dyslexic child (pp. 2140). Baltimore: Johns Hopkins Press.

NeIsser, U. (1967). Cognitive psychology. New York: AppletonCentury-Crofts.

Pomerantz, J., \& Garner, W. (1973). Stimulus configuration in selective attention tasks. Perception \& Psychophysics, 14, 565-569.

Preston, M. S., Guthrie, J. T., \& ChILDS, B. (1974). Visual evoked responses (VERs) in normal and disabled readers. Psychophysiology, $11,452-457$

Satz, P., Sparrow, S. (1970). Specific developmental dyslexia: A theoretical formulation. In D. J. Bakker \& P. Satz (Eds.), Specific reading disability: Advances in theory and method (pp. 12-32). Rotterdam: University of Rotterdam Press.

SовотKA, K. R., MAY, J. G. (1977). Visual evoked potentials and reaction time in normal and dyslexic children. Psychophysiology, 14, 18-24.

STANLEY, G., \& HALL, R. (1973). Short-term visual information processing in dyslexics. Child Development, 44, 841-844.

Symann-Louett, N., Gascon, G. G., Matsumty, Y., \& Lombroso, C. T. (1977). Wave form difference in visual evoked responses between normal and reading disabled children. Neurology, 27, 156-159. Vellutino, F. R. (1987). Dyslexia. Scientific American, 256(3), 34-41.

Weisstein, N., OzoG, G., \& SzoG, R. (1975). A comparison and evaluation of two models of metacontrast. Psychological Review, 82, 325-343.

Williams, M. C., \& Bologna, N. (1985). Perceptual grouping effects in good and poor readers. Perception \& Psychophysics, 38, 367-374.

Williams, M. C., \& Brannan, J. R. (1986, November). Global precedence in good and poor readers. Paper presented at the annual meeting of the Psychonomic Society, New Orleans.

Williams, M. C., Brannan, J. R., \& Lartigue, E. K. (1987). Visual search in good and poor readers. Clinical Vision Sciences, 1, 367-371.

(Manuscript received September 29, 1987; revision accepted for publication May 17, 1988.) 